\title{
Structural Health Monitoring of Civil Infrastructure Using Optical Fiber Sensing Technology: A Comprehensive Review
}

\author{
X. W. Ye, ${ }^{1}$ Y. H. Su, ${ }^{2}$ and J. P. Han ${ }^{2}$ \\ ${ }^{1}$ Department of Civil Engineering, Zhejiang University, Hangzhou 310058, China \\ ${ }^{2}$ Key Laboratory of Disaster Prevention and Mitigation in Civil Engineering of Gansu Province, \\ Lanzhou University of Technology, Lanzhou 730050, China \\ Correspondence should be addressed to X. W. Ye; cexwye@zju.edu.cn
}

Received 28 March 2014; Accepted 10 June 2014; Published 14 July 2014

Academic Editor: Ting-Hua Yi

Copyright (C) 2014 X. W. Ye et al. This is an open access article distributed under the Creative Commons Attribution License, which permits unrestricted use, distribution, and reproduction in any medium, provided the original work is properly cited.

\begin{abstract}
In the last two decades, a significant number of innovative sensing systems based on optical fiber sensors have been exploited in the engineering community due to their inherent distinctive advantages such as small size, light weight, immunity to electromagnetic interference (EMI) and corrosion, and embedding capability. A lot of optical fiber sensor-based monitoring systems have been developed for continuous measurement and real-time assessment of diversified engineering structures such as bridges, buildings, tunnels, pipelines, wind turbines, railway infrastructure, and geotechnical structures. The purpose of this review article is devoted to presenting a summary of the basic principles of various optical fiber sensors, innovation in sensing and computational methodologies, development of novel optical fiber sensors, and the practical application status of the optical fiber sensing technology in structural health monitoring (SHM) of civil infrastructure.
\end{abstract}

\section{Introduction}

Structural health monitoring (SHM) has been a fastdeveloping domain in engineering disciplines especially in civil engineering field. The innovation in the SHM technologies as well as the development of the large-scale SHM systems has boomed within the engineering and academic communities over the last two decades [1-7]. The available practical experiences have proved that the progressive advancement of the sensing techniques will undoubtedly expedite the evolution of the SHM technology. In comparison with the traditional mechanical and electrical sensors, the optical fiber sensors possess some unique advantages such as small size, light weight, immunity to electromagnetic interference (EMI) and corrosion, and embedding capability [8-12], and therefore they have been employed in monitoring of engineering structures worldwide. This paper will provide a comprehensive review on structural monitoring of civil infrastructure by use of the optical fiber sensing technology.

In the last two decades, a considerable number of investigations have been conducted in reviewing the progress of research and development of the optical fiber sensing technology as well as the applications of optical fiber sensors in the monitoring of various kinds of engineering structures [13-17]. Bhatia et al. [18] reported the progress in the performance and reliability of the optical fiber-based extrinsic Fabry-Perot interferometric (EFPI) strain sensor. Rao [19] gave a systematic review of progress on applications of FBG sensors in large composite and concrete structures, the electrical power industry, medicine, and chemical sensing. Leung [20] reviewed the applications of optical fiber sensors for monitoring of concrete structures. Measures et al. [21] overviewed the research on the development of structurally integrated optical fiber sensors for the smart structures. Merzbacher et al. [22] reviewed the strain monitoring of concrete structures by use of optical fiber sensors. LópezHiguera et al. [23] summarized the main types of optical fiber techniques suitable for structural monitoring and introduced various optical fiber sensor-based engineering application scenarios. Ansari [24] provided a summary of basic principles pertaining to monitoring of civil engineering structures with optical fiber sensors. Majumder et al. [25] reviewed the recent 


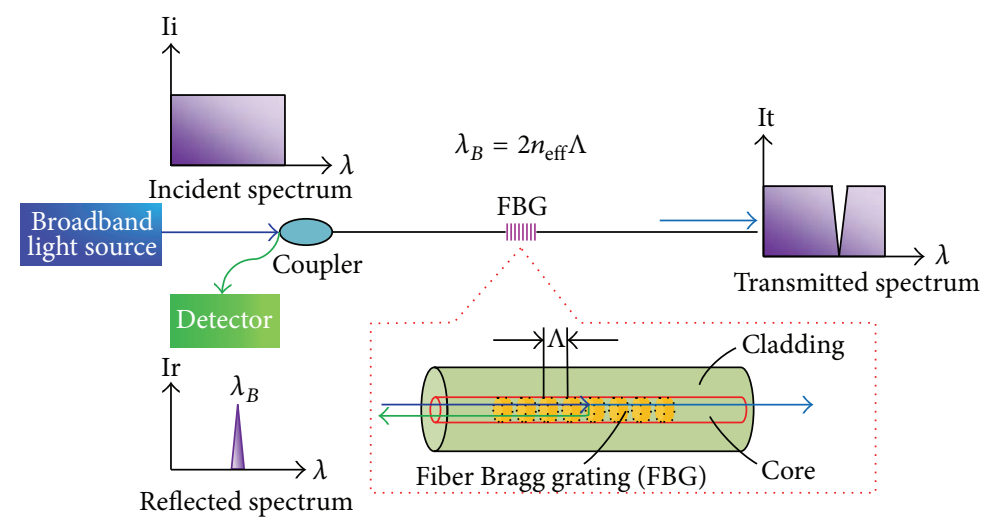

FIGURE 1: Measurement principal of FBG sensor.

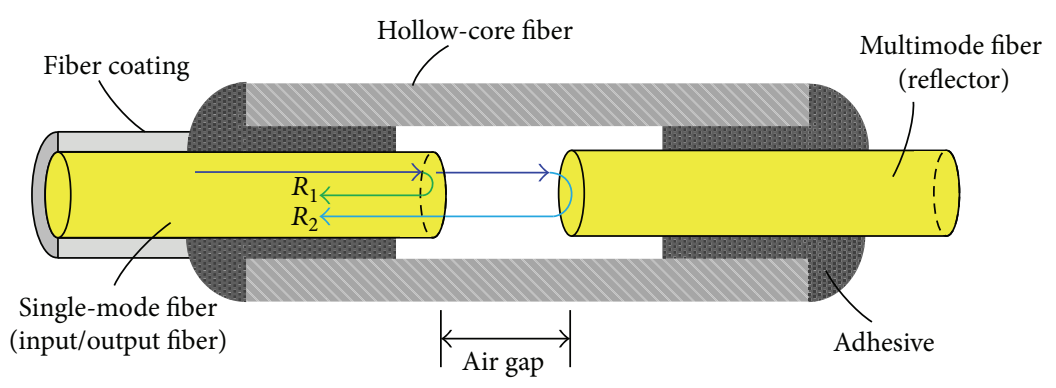

FIGURE 2: Measurement principal of EFPI sensor.

research and development activities in structural monitoring using FBG sensors.

\section{Fundamentals of Optical Fiber Sensors}

Generally, an optical fiber sensor system consists of a light transmitter, a receiver, an optical fiber, a modulator element, and a signal processing unit. As the core part of an optical fiber sensor, the optical fiber is usually made from silica glass or polymer material, which itself can act as a sensing element or carry the light from the source to the modulator element. When the strain or temperature variation of the structure occurs, the surface-mounted or embedded optical fiber sensor in the structure will expand or contract. In accordance with the change of the length of the optical fiber, the optical fiber sensor modulates the light and reflects back an optical signal to the analytical unit for deriving the concerned physical quantity of the structure [26]. Based on the sensing principle, the optical fiber sensors can be categorized into different types as illustrated in the following sections [27].

2.1. Fiber Bragg Grating (FBG) Sensors. Up to now, the FBG sensor has been widely used in the monitoring of civil engineering structures [28-32]. It can be regarded as a type of optical fiber sensor with varied refractive indices in the core. According to Bragg's law, a beam of white light is written in the FBG sensor, and when the light from the broadband source passes through the grating at a particular wavelength, the Bragg wavelength is reflected which is related to the grating period, as illustrated in Figure 1. The Bragg wavelength $\lambda_{B}$ can be expressed by

$$
\lambda_{B}=2 n_{\mathrm{eff}} \Lambda
$$

where $n_{\text {eff }}$ is the effective index of refraction and $\Lambda$ is the grating period. The wavelength shift changes linearly with both strain and temperature. When the grating part is subjected to external disturbance, the period of the grating will be changed and the Bragg wavelength is varied accordingly. The variation of the Bragg wavelength can be obtained by

$$
\Delta \lambda_{B}=\lambda_{B}\left\{(\alpha+\xi) \Delta T+\left(1-p_{e}\right) \Delta \varepsilon\right\}
$$

where $\Delta \varepsilon$ is the strain variation, $\Delta T$ is the temperature change, $\alpha$ is the coefficient of the thermal expansion, $\xi$ is the thermooptic coefficient, and $p_{e}$ is the strain-optic coefficient.

2.2. Extrinsic Fabry-Perot Interferometric (EFPI) Sensors. For an EFPI sensor, the optical fiber acts as the input or output path; the light from the source passes through the optical fiber to the sensing part and then to the demodulation system [33-38]. A typical EFPI sensor consists of the input/output fibers and the reflective fibers as well as a hollow-core tube for creating an air cavity, namely, the Fabry-Perot cavity. An adhesive is employed to bond the two components. As illustrated in Figure 2, the Fabry-Perot cavity is formed between an input single-mode fiber and a reflecting singlemode or multimode fiber, and two fibers are aligned inside 


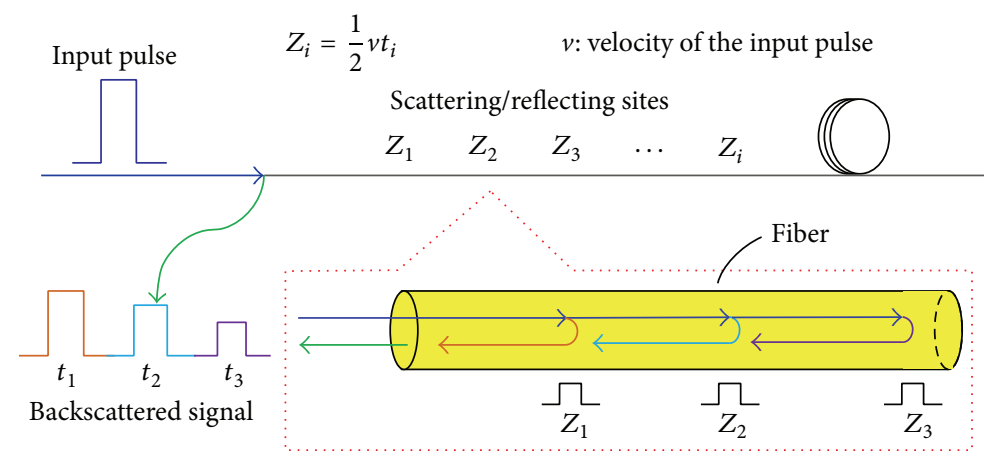

FIGURE 3: Measurement principal of OTDR sensor.

a hollow-core tube. At both ends of the cavity, there are reflections on the uncoated ends of the fibers. $R_{1}$ is referred to as the reference reflection which depends on the applied perturbation such as strain and temperature. $R_{2}$ is the sensing reflection and depends on the length of the cavity, $L$. A sinusoidal output signal will be generated when $R_{1}$ interferes with $R_{2}$. Because the length of the cavity can be modulated by the applied perturbation, the EFPI sensor can be used to measure the applied perturbation according to the output signal. For the strain measurement, it can be expressed by

$$
\varepsilon=\frac{\Delta l(\text { air gap })}{L},
$$

where $\Delta l$ is the variation in the cavity.

2.3. Optical Time-Domain Reflectometry (OTDR) Sensors. An optical time-domain reflectometry- (OTDR-) based sensor is capable of distributedly sensing along the length of an optical fiber with a specific refractive index $[39,40]$. When a light pulse at a particular wavelength propagates along the optical fiber, the sensor can locate the position of the interaction according to the propagation time, as illustrated in Figure 3. The location of the variation of the measurand may be determined by the OTDR sensor. The OTDR-based distributed sensor is possible to be used to measure the change in the properties of the light along the entire optical fiber by measuring the time of flight of the returned pulses. The Brillouin optical time domain reflectometer (BOTDR) sensor is one of the distributed optical fiber sensors and is based on the Brillouin scattering. Due to the advantage of being capable of measuring continuous strain and temperature over a long distance, the BOTDR sensor has been widely applied in distributed monitoring of large-scale civil structures.

\section{Innovation in Methodologies and Sensors}

3.1. Improvement of Methods. Li et al. [41] proposed a theoretical model for describing the strain transfer relationship between the fiber core of the FBG sensor and the host material. Yun et al. [42] developed a new method based on the simulated annealing evolutionary algorithm for demodulation of the strain profile along an FBG distributed strain sensor. Imai and Feng [43] proposed a stress-transferring model incorporating drastic softening behavior for the surrounding components to investigate the stress transfer from a host structure to a sensing fiber. Zhang et al. [44] proposed a model reconstruction soft computing recognition algorithm based on genetic algorithm, support vector regression to achieve the reliability of the FBG-based sensor network. Gill et al. [45] presented a genetic algorithm for the inversion of Bragg grating sensor spectral data to determine the strain distribution along the grating. Prabhugoud and Peters [46] developed an integrated formulation for the calculation of the spectral response of an FBG sensor embedded in a host material system as a function of the loading applied to the host structure.

Liu et al. [47] proposed an adaptive filtering algorithm for the noise reduction and the detectability of seismic signals measured by an FBG measuring system. Ma et al. [48] presented a fast interrogation method for the dynamic and/or static strain gauge by use of a reflection spectrum from two superimposed FBGs. Jang et al. [49] developed a real-time impact localization algorithm for various composite structures using the impact-induced acoustic signals acquired by multiplexed FBG sensors. Schizas et al. [50] proposed a method for nonhomogeneous strain monitoring of composite structures with embedded wavelength multiplexed FBG sensors. Feng et al. [51] proposed a stationary wavelet transform method for signal processing of the distributed strain data from the BOTDR-based optical fiber sensors. Peters et al. [52] investigated the method of measurement of nonuniform strain field near the stress concentration by use of the embedded FBG sensor.

3.2. Development of Sensors. Lee et al. [53] developed an optical fiber accelerometer composed of a reflective grating panel and two optical fibers as transceivers which was capable of monitoring the low-frequency acceleration of large-scale civil engineering structures. Wang and Huang [54] developed an optical fiber corrosion sensor based on the principle of light reflection consisting of an optical fiber reflection sensor and a tube/film subassembly formed by welding a sacrificial metallic film to a steel tube. Rodriguez-Cobo et 
al. [55] designed an FBG-based smart structure embedded into composite laminates for simultaneous measurement of temperature and strain and conducted experimental investigations for performance validation. Pirozzi [56] developed a multipoint force sensor based on crossed optical fibers. Kim et al. [57] developed a gold-deposited extrinsic Fabry-Perot interferometer for dynamic strain measurement.

Cumunel et al. [58] investigated the capacity of continuously attached long-gauge optical fiber sensors for dynamic evaluation of structures. Gangopadhyay et al. [59] addressed different design and experimental packaging procedures of indigenously developed FBG sensors for strain measurement. Yuan et al. [60] presented an optical fiber two-dimensional sensing system for measuring the strain inside the concrete structure based on white-light Michelson interferometric optical fiber sensing technique. Liu et al. [61] designed a longperiod fiber grating sensor for detecting the state of rebar corrosion in concrete. Yashiro et al. [62] proposed an embedded chirped FBG sensor for damage detection in the holed carbon fiber reinforced polymer (CFRP) laminate. Zhou et al. [63] designed an extrinsic Fabry-Perot interferometric strain sensor for damage evaluation of smart composite beams. Triollet et al. [64] proposed a superimposed FBG device to measure, localize, and discriminate strain and temperature effects simultaneously for structural monitoring.

Hong et al. [65] developed a distributed long-gauge FBG macrostrain sensor for condition assessment of reinforced concrete beams [66]. Quirion and Ballivy [67] validated the robustness of the Fabry-Perot optical fiber sensor in strain monitoring of the concrete structure. Davis et al. [68] developed an integrated FBG-based sensing system for broad area damage detection of composite structures. Villalba and Casas [69] evaluated the usefulness and effectiveness of the optical backscatter reflectometer sensor in damage detection of concrete structures. Torres et al. [70] presented a new FBG strain sensor with an unsymmetrical packaging configuration designed to be fixed to the surface of the monitored structure. Schröder et al. [71] developed a low-cost optical fiber sensing system for continuous on-site monitoring of contact forces in current collectors. Kim [72] developed a smart monitoring system for stress monitoring and damage detection of offshore structures using piezoceramic and optical fiber sensors.

$\mathrm{Xu}$ et al. [73] developed a novel Fabry-Perot optical fiber pressure sensor for application in high temperature environments. García et al. [74] developed a novel distributed optical fiber strain sensor suitable for long-distance condition monitoring of engineering structures. Liu et al. [75] developed a partially multiplexed EFPI-based optical fiber strain sensor system for in situ strain measurement of composite structures. Sun et al. [76] experimentally investigated the feasibility of corrosion monitoring of reinforced concrete structures by use of BOTDR sensors. Lan et al. [77] developed a combined Brillouin and FBG sensor for the monitoring of structural prestress loss in reinforced concrete beams. Zhou et al. [78] developed a smart fiber reinforced polymer (FRP) rebar with an embedded novel optical fiber for evaluation of prestress loss distribution in posttensioned concrete structures.

\section{Applications of Optical Fiber Sensing Technology}

4.1. Bridges. As the vital hinges of the transportation lines, the health conditions of the bridges have always been concerned by the bridge owners and managers. Continuous real-time monitoring of the environmental and operational loadings as well as the structural responses and behaviors of the bridges has been proved to be a promising and effective way for system identification, damage detection, safety condition assessment, and structural performance prediction. Due to the nonsubstitutable capabilities and unique advantages, the optical fiber sensing technology has been served as an effective tool for the monitoring of each phase of the bridge lifecycle (construction, operation, reinforcement, and rehabilitation), of various structural components of bridges (decks, towers, stay cables, suspenders, girders, piers, piles, and abutments), and of different measurands (strains, temperatures, accelerations, deflections/displacements, cracks, and corrosion). There have been a lot of investigations on bridge health monitoring and structural condition assessment based on the optical fiber sensing technology as detailed in the following sections.

4.1.1. Integrated Bridge Monitoring System. A considerable number of optical fiber-based integrated SHM systems deployed on various types of bridges have been developed worldwide [79]. In USA, Mehrani et al. [80] developed a remote monitoring system based on optical fiber sensors for condition assessment of bridges and the performance of the developed system was validated through field instrumentation on a bridge in Florida, USA, during its construction stage. Glisic and Inaudi [81] developed a method for integrity monitoring of fracture critical bridges using simulated Brillouin scattering based on a crack or local deformation identification algorithm and a sensor delamination mechanism. Talebinejad et al. [82] developed an FBG-based accelerometer by use of the stiffness of the optical fiber and a lumped mass and the performance of which was evaluated during ambient vibration tests of a real bridge. In Canada, a total of 16 bridges have been instrumented with long-term SHM systems by intelligent sensing for innovative structures (ISIS) with various combinations of optical fiber sensors [83].

Brönnimann et al. [84] investigated the reliability and long-term stability of an FBG-based sensing and surveillance system through a monitoring period of six months during construction of a stay cable in Switzerland. In Portugal, Rodrigues et al. [85] developed an FBG-based system with embedded displacement and strain transducers for long-term monitoring of structural performance of concrete bridges which was applied to a concrete bridge. Barbosa et al. [86] developed a novel weldable FBG sensing system for strain and temperature monitoring of steel bridges and for loading tests and health monitoring of a circular pedestrian steel bridge. In UK, Kerrouche et al. [87] developed a relatively cheap and effective sensing system using a compact FBGbased monitoring system incorporating a scanning FabryPerot filter, and the performance of the system was validated 
through laboratory experiments and field tests in a real bridge. Kister et al. $[88,89]$ conducted the research on structural monitoring of a composite road bridge by use of FBG sensors, and the performance of the adhesives and the protection system of the sensors were evaluated through field pullout tests. Mokhtar et al. [90] created an innovative FBG-based sensor system for accurate strain measurement with full temperature compensation towards condition monitoring and assessment of arch bridges. Surre et al. [91] developed an optical fiber sensor system for long-term strain monitoring and condition assessment of a redundant 50year-old concrete footbridge.

In Hong Kong, the high-speed demultiplexing/interrogation system for FBG sensor arrays and FBG sensor package units were deployed for long-term monitoring on the Tsing Ma Bridge which is the world's longest suspension bridge carrying both highway and railway traffic [92]. Yau et al. [93] proposed a simple, inexpensive, and practical method for measurement of the vertical displacement of bridges by use of FBG sensors. In Chinese mainland, Zhao et al. [94] integrated the distributed Brillouin optical time domain analysis (BOTDA) technology and the FBG sensing technology for strain monitoring of bridges. In Korea, Chung et al. [95] conducted the experimental study on the applicability of long-gauge optical fiber sensors for the monitoring of the structural defection of the prestressed concrete bridges. Lin et al. [96] developed an FBG-based sensing system for online monitoring of highway bridges during construction to record the hydration effects, curing periods, prestressing responses, and removal of support frames.

4.1.2. Monitoring of Rehabilitated and Antique Bridges. Research efforts also have been devoted to measuring the structural behaviors of old bridges or deficient bridges during rehabilitation by use of the optical fiber sensing system [97]. Jiang et al. [98] applied two types of optical fiber sensors embedded in FRP material to monitor the global and local behaviors of the strengthened bridge structures. Zhang et al. [99] introduced two types of optical fiber sensing technologies (FBG and BOTDR) for health monitoring of rehabilitated reinforced concrete girder bridges, and the static and dynamic loading tests were carried out with a simply supported reinforced concrete T-beam strengthened by externally posttensioned aramid fiber reinforced polymer (AFRP). Costa and Figueiras [100] presented the design of an advanced FBG-based monitoring system which was applied to a century steel arch bridge in Portugal.

4.1.3. Monitoring of Bridge Cables and Suspenders. He et al. [101] carried out an investigation on cable force monitoring by use of the local high-precision FBG sensor in combination with the distributed BOTDA sensing technique. Li et al. [102] developed a smart stay cable assembled with FBG-based strain and temperature sensors which were incorporated into a glass fiber reinforced polymer (GFRP) bar. The efficiency of the developed smart stay cable was proved by application to evaluate the fatigue accumulative damage of a stay cable bridge in China $[103,104]$.
4.1.4. Bridge Scour Monitoring. Zhou et al. [105] proposed an FBG sensing system for scour monitoring of foundations of bridge piers and abutments. This developed system introduced a uniform-strength FRP beam instrumented with two FBG sensors in two sides of the neutral axis, and the feasibility of the system was validated through laboratory tests. Lin et al. $[106,107]$ developed two types of FBG-based systems for real-time bridge scour monitoring, which were capable of measuring the process of scouring/deposition and the variation of the water level. The in situ FBG scour monitoring system was demonstrated to be robust and reliable for realtime scour-depth measurement and to be valid for indicating the depositional depth. Xiong et al. [108] developed a bridge scour monitoring system by use of FBG sensors, and the experimental investigations verified that the recommended scour monitoring system was capable of measuring the water level, the scour depth, the entire process of scour development, and the deposition height due to the refilling process.

4.2. Buildings. The optical fiber sensing technology has been employed in safety condition monitoring of the highrise structures during in-construction and in-service stages. Bastianini et al. [109] utilized the embedded optical fiber Brillouin sensors for strain monitoring and crack detection of a historical building. Antunes et al. [110] conducted dynamic monitoring of a reinforced concrete water reservoir and a slender metallic telecommunication tower by use of FBGbased biaxial accelerometers. Ni et al. [111] deployed massive FBG sensors for strain and temperature monitoring of the Canton Tower. Li et al. [112] performed an investigation on the feasibility of the FBG-based monitoring system instrumented in an 18-floor tall building during construction. The FBG sensors were used to monitor the strain and temperature of the building in three steps of construction, that is, before the concrete pouring, during the pouring and curing of concrete, and the construction of subsequent upper floors of the building.

4.3. Tunnels and Pipelines. Ye et al. [113] addressed two engineering paradigms on safety monitoring of tunnel construction by use of FBG sensors. Metje et al. [114] presented a new optical fiber sensing system for structural displacement monitoring which was successfully applied to measure the displacement of a tunnel lining. The novel system was based on a square fiberglass smart rod which was proved sensitive enough to measure the rotational movement of $0.5^{\circ}$ and the lateral movement of $0.1 \mathrm{~mm}$ of the fixings. Li et al. [115] developed a metal groove encapsulating technique for the bare FBG sensor to measure the surface strain of the second lining of the tunnel. Li et al. [116] developed a differential FBG strain sensor for monitoring the stability of the tunnel during the backfilling and traffic-operating periods.

Glisic and Yao [117] proposed a method for real-time, automatic, or on-demand assessment of health conditions of buried pipelines after the earthquake based on distributed optical fiber sensors, the research of determination of sensor topologies, selection and development of sensors, 
development of installation and implementation procedures, and large-scale tests were conducted. Zhang et al. [118] experimentally investigated the prediction of locations and progression sequences of the pipe buckling with the aid of the broadening factor of the Brillouin spectrum width using high strength carbon-coated fibers and standard communication fibers.

4.4. Wind Turbines. A review of the current status and a discussion on research and implementation of FBGs and long-period gratings in wind turbine blade sensors can be found in [119]. Arsenault et al. [120] developed an FBG-based distributed strain sensor system for real-time monitoring of a wind turbine and conducted the validation tests under a laboratory scale under various loading conditions. Kim et al. [121] conducted experimental investigations on deflection estimation of wind turbine blades using embedded FBG sensors. Burgmeier et al. [122] developed and tested an FBGbased sensor system for remote measurement of strain that affects the power cable in an offshore wind turbine.

Bang et al. [123] introduced an FBG-based arrayed sensor system for measurement of strain and bending deflection of wind turbine towers. Ge et al. [124] developed a specific intensity-modulated optical fiber accelerometer for vibration monitoring of wind turbine blades. Schroeder et al. [125] installed an FBG measurement system for load monitoring in horizontal-axis wind turbines. Choi et al. [126] determined the tip deflections of a composite wind turbine blade through a static load test using mechanical strains measured by FBG sensor probes.

4.5. Railway Infrastructure. Recently, the optical fiber sensorbased monitoring system has attracted great interests among the researchers in the fields of railway engineering and optical engineering. Yan et al. [127] proposed three FBG-based methods for strain measurement and axle counting in highspeed railway systems, and the advantages and limitations of these approaches were discussed in terms of feasibility and cost-effectiveness through laboratory verification and evaluation. Wei et al. [128, 129] described a real-time wheel defect detection system through deploying FBG sensors on rail tracks of the Hong Kong mass transit railway (MTR) to gain the track strains upon wheel-rail interaction and generate a reliable condition index reflecting the wheel condition, and the effectiveness of the introduced system was verified by extensive field tests. Filograno et al. [130] implemented an FBG-based railway security monitoring system on the Spanish high-speed line Madrid-Barcelona for train identification, axle counting, speed and acceleration detection, wheel imperfection monitoring, and dynamic load calculation.

Pimentel et al. [131] developed a hybrid fiberoptic/electrical train characterization system with a new weight-in-motion (WIM) algorithm for on-motion determination of the train speed, acceleration and weight distribution for traffic monitoring, and safety evaluation of a railway bridge in Portugal. Kerrouche et al. [132, 133] conducted the research on structural monitoring of a decommissioned concrete railway bridge in Sweden loaded to failure by use of an FBG-based distributed sensor system.

Kang and Chung [134] developed an integrated FBGbased monitoring scheme for a maglev guideway in Korea to measure the parameters involving strains, curvatures, vertical defections, and frequencies which were compared with those obtained from the conventional sensors [135]. Yoon et al. [136] proposed a distributed Brillouin optical correlation domain analysis- (BOCDA-) based sensing system to measure the longitudinal strain distribution of a rail in real time, and the results of a spatial resolution of $3.8 \mathrm{~cm}$ and an accuracy of $\pm 15 \mu \varepsilon$ were achieved under different loading conditions applied to a $2.8 \mathrm{~m}$ rail. Wang et al. [137] utilized $A$-thermal FBG sensors and electronic sensors to record performance changes in the continuous welded rail, and the monitoring results revealed that the optical fiber sensor was durable and capable of long-term monitoring and was capable of providing sensitive, clear, and stable signals.

Bocciolone et al. [138] presented the application of FBG sensors on a pantograph for monitoring of the contact force and the vertical acceleration of the pantograph head of the pantograph-catenary system in an underground line. Boffi et al. [139] developed an innovative optical fiber sensor-based system for online monitoring of the contact force between the pantograph and the catenary at low and high frequencies.

4.6. Geotechnical Structures. Regarding the applications in geotechnical engineering, Pei et al. $[140,141]$ developed an FBG-based in-place inclinometer for lateral displacement measurement of slopes in accordance with the classical indeterminate beam theory which was successfully installed in a slope in China for long-term displacement monitoring. Kister et al. [142] deployed FBG sensors in reinforced concrete foundation piles for strain and temperature monitoring and structural health condition assessment. Lu et al. [143] conducted the field measurement of the stress within the precast pile by use of the BOTDR-based optical fiber sensing technique. Kim et al. [144] developed a specially designed FBG-embedded tendon for the monitoring of the prestress force and load transfer of the ground anchor and the feasibility of the device was verified through laboratory and field tests. Legge et al. [145] developed an FBG-based stress cell for determination of the full state of three-dimensional stress at any accessible or predetermined point in a soil mass or structure.

\section{Conclusions}

This paper provides a summary of the research and development in the area of structural monitoring of civil infrastructure by use of the optical fiber sensing technology. Based on a comprehensive review of the optical fiber sensorbased theories, methods, technologies, and applications, the following concluding remarks are made: (i) due to their unique merits, the optical fiber sensors have been widely used in life-cycle monitoring of civil infrastructure such as bridges, buildings, tunnels, pipelines, wind turbines, railway infrastructure, and geotechnical structures; (ii) the optical 
fiber sensing technology is capable of measuring lots of types of measurands such as strains, temperatures, accelerations, deflections/displacements, cracks, and corrosion; and (iii) the exploitation of protection measures in sensor installation as well as the development of cost-effective optical fiber demodulation instruments are desirable in the further research.

\section{Conflict of Interests}

The authors declare that there is no conflict of interests regarding the publication of this paper.

\section{Acknowledgments}

The work described in this paper was jointly supported by the National Science Foundation of China (Grant nos. 51308493 and U1234204), the Research Fund for the Doctoral Program of Higher Education of China (Grant no. 20130101120080), and the Fundamental Research Funds for the Central Universities of China (Grant no. 2013QNA4023).

\section{References}

[1] Y. Q. Ni, X. W. Ye, and J. M. Ko, "Monitoring-based fatigue reliability assessment of steel bridges: analytical model and application," Journal of Structural Engineering, vol. 136, no. 12, pp. 1563-1573, 2010.

[2] Y. Q. Ni, X. W. Ye, and J. M. Ko, "Modeling of stress spectrum using long-term monitoring data and finite mixture distributions," Journal of Engineering Mechanics, vol. 138, no. 2, pp. 175183, 2012.

[3] X. W. Ye, Y. Q. Ni, K. Y. Wong, and J. M. Ko, "Statistical analysis of stress spectra for fatigue life assessment of steel bridges with structural health monitoring data," Engineering Structures, vol. 45, pp. 166-176, 2012.

[4] X. W. Ye, Y. Q. Ni, T. T. Wai, K. Y. Wong, X. M. Zhang, and $\mathrm{F} . \mathrm{Xu}$, "A vision-based system for dynamic displacement measurement of long-span bridges: algorithm and verification," Smart Structures and Systems, vol. 12, no. 3-4, pp. 363-379, 2013.

[5] H. N. Li, T. H. Yi, L. Ren, D. S. Li, and L. S. Huo, "Reviews on innovations and applications in structural health monitoring for infrastructures," Structural Monitoring and Maintenance, vol. 1, no. 1, pp. 1-45, 2014.

[6] T. H. Yi, H. N. Li, and M. Gu, "Recent research and applications of GPS-based monitoring technology for high-rise structures," Structural Control and Health Monitoring, vol. 20, no. 5, pp. 649670, 2013

[7] T. H. Yi, H. N. Li, and H. M. Sun, "Multi-stage structural damage diagnosis method based on "energy-damage" theory," Smart Structures and Systems, vol. 12, no. 3-4, pp. 345-361, 2013.

[8] J. M. Nichols, S. T. Trickey, M. Seaver, and L. Moniz, "Use of fiber-optic strain sensors and holder exponents for detecting and localizing damage in an experimental plate structure," Journal of Intelligent Material Systems and Structures, vol. 18, no. 1, pp. 51-67, 2007.

[9] H. Murayama, K. Kageyama, K. Uzawa, K. Ohara, and H. Igawa, "Strain monitoring of a single-lap joint with embedded fiberoptic distributed sensors," Structural Health Monitoring, vol. 11, no. 3, pp. 325-344, 2011.
[10] R. A. Silva-Muñoz and R. A. Lopez-Anido, "Structural health monitoring of marine composite structural joints using embedded fiber Bragg grating strain sensors," Composite Structures, vol. 89, no. 2, pp. 224-234, 2009.

[11] C. Pang, M. Yu, A. K. Gupta, and K. M. Bryden, "Investigation of smart multifunctional optical sensor platform and its application in optical sensor networks," Smart Structures and Systems, vol. 12, no. 1, pp. 23-39, 2013.

[12] A. Khiat, F. Lamarque, C. Prelle, P. Pouille, M. Leester-Schädel, and S. Büttgenbach, "Two-dimension fiber optic sensor for high-resolution and long-range linear measurements," Sensors and Actuators A: Physical, vol. 158, no. 1, pp. 43-50, 2010.

[13] F. Ansari, "State-of-the-art in the applications of fiber-optic sensors to cementitious composites," Cement and Concrete Composites, vol. 19, no. 1, pp. 3-19, 1997.

[14] X. Bao and L. Chen, "Recent progress in Brillouin scattering based fiber sensors," Sensors, vol. 11, no. 4, pp. 4152-4187, 2011.

[15] K. T. V. Grattan and T. Sun, "Fiber optic sensor technology: an overview," Sensors and Actuators, A: Physical, vol. 82, no. 1, pp. 40-61, 2000.

[16] L. Deng and C. S. Cai, "Applications of fiber optic sensors in civil engineering," Structural Engineering and Mechanics, vol. 25, no. 5, pp. 577-596, 2007.

[17] H. N. Li, D. S. Li, and G. B. Song, "Recent applications of fiber optic sensors to health monitoring in civil engineering," Engineering Structures, vol. 26, no. 11, pp. 1647-1657, 2004.

[18] V. Bhatia, K. A. Murphy, R. O. Claus, T. A. Tran, and J. A. Greene, "Recent developments in optical-fiber-based extrinsic Fabry-Perot interferometric strain sensing technology," Smart Materials and Structures, vol. 4, no. 4, pp. 246-251, 1995.

[19] Y. J. Rao, "Recent progress in applications of in-fibre Bragg grating sensors," Optics and Lasers in Engineering, vol. 31, no. 4, pp. 297-324, 1999.

[20] C. K. Y. Leung, "Fiber optic sensors in concrete: the future?" NDT \& E International, vol. 34, no. 2, pp. 85-94, 2001.

[21] R. M. Measures, M. LeBlanc, K. Liu et al., "Fiber optic sensors for smart structures," Optics and Lasers in Engineering, vol. 16, no. 2-3, pp. 127-152, 1992.

[22] C. I. Merzbacher, A. D. Kersey, and E. J. Friebele, "Fiber optic sensors in concrete structures: a review," Smart Materials and Structures, vol. 5, no. 2, pp. 196-208, 1996.

[23] J. M. López-Higuera, L. R. Cobo, A. Q. Incera, and A. Cobo, "Fiber optic sensors in structural health monitoring," Journal of Lightwave Technology, vol. 29, no. 4, pp. 587-608, 2011.

[24] F. Ansari, "Practical implementation of optical fiber sensors in civil structural health monitoring," Journal of Intelligent Material Systems and Structures, vol. 18, no. 8, pp. 879-889, 2007.

[25] M. Majumder, T. K. Gangopadhyay, A. K. Chakraborty, K. Dasgupta, and D. K. Bhattacharya, "Fibre Bragg gratings in structural health monitoring-present status and applications," Sensors and Actuators A: Physical, vol. 147, no. 1, pp. 150-164, 2008.

[26] Q. B. Li and F. Ansari, "Circumferential strain measurement of high strength concrete in triaxial compression by fiber optic sensor," International Journal of Solids and Structures, vol. 38, no. 42-43, pp. 7607-7625, 2001.

[27] D. C. Lee, J. J. Lee, and I. B. Kwon, "Monitoring of fatigue crack growth in steel structures using intensity-based optical fiber sensors," Journal of Intelligent Material Systems and Structures, vol. 11, no. 2, pp. 100-107, 2000. 
[28] S. Jacobs, S. Matthys, G. De Roeck, L. Taerwe, W. de Waele, and J. Degrieck, “Testing of a prestressed concrete girder to study the enhanced performance of monitoring by integrating optical fiber sensors," Journal of Structural Engineering, vol. 133, no. 4, pp. 541-549, 2007.

[29] P. Moyo, J. M. W. Brownjohn, R. Suresh, and S. C. Tjin, "Development of fiber Bragg grating sensors for monitoring civil infrastructure," Engineering Structures, vol. 27, no. 12, pp. 1828-1834, 2005.

[30] D. C. Betz, L. Staudigel, M. N. Trutzel, and M. Kehlenbach, "Structural monitoring using fiber-optic bragg grating sensors," Structural Health Monitoring, vol. 2, no. 2, pp. 145-152, 2003.

[31] M. D. Todd, G. A. Johnson, and S. T. Vohra, "Deployment of a fiber bragg grating-based measurement system in a structural health monitoring application," Smart Materials and Structures, vol. 10, no. 3, pp. 534-539, 2001.

[32] P. Capoluongo, C. Ambrosino, S. Campopiano et al., "Modal analysis and damage detection by Fiber Bragg grating sensors," Sensors and Actuators A: Physical, vol. 133, no. 2, pp. 415-424, 2007.

[33] K. Kesavan, K. Ravisankar, S. Parivallal, and P. Sreeshylam, "Applications of fiber optic sensors for structural health monitoring," Smart Structures and Systems, vol. 1, no. 4, pp. 355-368, 2005.

[34] I. B. Kwon, M. Y. Choi, and H. Moon, "Strain measurement using fiber optic total reflected extrinsic Fabry-Perot interferometric sensor with a digital signal processing algorithm," Sensors and Actuators A: Physical, vol. 112, no. 1, pp. 10-17, 2004.

[35] T. Liu, D. Brooks, A. Martin, R. Badcock, B. Ralph, and G. F. Fernando, "A multi-mode extrinsic Fabry-Pérot interferometric strain sensor," Smart Materials and Structures, vol. 6, no. 4, pp. 464-469, 1997.

[36] M. Z. Jiang and E. Gerhard, "Simple strain sensor using a thin film as a low-finesse fiber-optic Fabry-Perot interferometer," Sensors and Actuators A: Physical, vol. 88, no. 1, pp. 41-46, 2001.

[37] F. Akhavan, S. E. Watkins, and K. Chandrashekhara, "Measurement and analysis of impact-induced strain using extrinsic Fabry-Pérot fiber optic sensors," Smart Materials and Structures, vol. 7, no. 6, pp. 745-751, 1998.

[38] V. Bhatia, K. A. Murphy, R. O. Claus et al., "Multiple strain state measurements using conventional and absolute optical fiberbased extrinsic Fabry-Perot interferometric strain sensors," Smart Materials and Structures, vol. 4, no. 4, pp. 240-245, 1995.

[39] A. Güemes, A. Fernández-López, and B. Soller, "Optical fiber distributed sensing-physical principles and applications," Structural Health Monitoring, vol. 9, no. 3, pp. 233-245, 2010.

[40] Z. Zhu, D. Liu, Q. Yuan, B. Liu, and J. Liu, "A novel distributed optic fiber transduser for landslides monitoring," Optics and Lasers in Engineering, vol. 49, no. 7, pp. 1019-1024, 2011.

[41] H. Li, G. Zhou, L. Ren, and D. Li, "Strain transfer coefficient analyses for embedded fiber bragg grating sensors in different host materials," Journal of Engineering Mechanics, vol. 135, no. 12, pp. 1343-1353, 2009.

[42] B. Yun, Y. Wang, A. Li, and Y. Cui, "Simulated annealing evolutionary algorithm for the fibre Bragg grating distributed strain sensor," Measurement Science and Technology, vol. 16, no. 12, pp. 2425-2430, 2005.

[43] M. Imai and M. Feng, "Sensing optical fiber installation study for crack identification using a stimulated Brillouin-based strain sensor," Structural Health Monitoring, vol. 11, no. 5, pp. 501-509, 2012.
[44] X. L. Zhang, D. K. Liang, J. Zeng, and A. Asundi, "Genetic algorithm-support vector regression for high reliability SHM system based on FBG sensor network," Optics and Lasers in Engineering, vol. 50, no. 2, pp. 148-153, 2012.

[45] A. Gill, K. Peters, and M. Studer, "Genetic algorithm for the reconstruction of Bragg grating sensor strain profiles," Measurement Science and Technology, vol. 15, no. 9, pp. 18771884, 2004.

[46] M. Prabhugoud and K. Peters, "Finite element model for embedded fiber Bragg grating sensor," Smart Materials and Structures, vol. 15, no. 2, pp. 550-562, 2006.

[47] J. G. Liu, C. Schmidt-Hattenberger, and G. Borm, "Dynamic strain measurement with a fibre Bragg grating sensor system," Measurement, vol. 32, no. 2, pp. 151-161, 2002.

[48] Y. C. Ma, Y. H. Yang, J. M. Li, M. W. Yang, J. Tang, and T. Liang, "Dynamic and static strain gauge using superimposed fiber Bragg gratings," Measurement Science and Technology, vol. 23, no. 10, Article ID 105202, 2012.

[49] B. W. Jang, Y. G. Lee, J. H. Kim, Y. Y. Kim, and C. G. Kim, "Realtime impact identification algorithm for composite structures using fiber Bragg grating sensors," Structural Control and Health Monitoring, vol. 19, no. 7, pp. 580-591, 2012.

[50] C. Schizas, S. Stutz, J. Botsis, and D. Coric, "Monitoring of nonhomogeneous strains in composites with embedded wavelength multiplexed fiber Bragg gratings: a methodological study," Composite Structures, vol. 94, no. 3, pp. 987-994, 2012.

[51] X. Feng, X. T. Zhang, C. S. Sun, M. Motamedi, and F. Ansari, "Stationary wavelet transform method for distributed detection of damage by fiber-optic sensors," Journal of Engineering Mechanics, vol. 140, no. 4, pp. 1-11, 2014.

[52] K. Peters, M. Studer, J. Botsis, A. Iocco, H. Limberger, and R. Salathé, "Embeded optical fiber bragg grating sensor in a nonuniform strain field: measurements and simulations," Experimental Mechanics, vol. 41, no. 1, pp. 19-28, 2001.

[53] Y. Lee, D. Kim, and C. Kim, "Performance of a single reflective grating-based fiber optic accelerometer," Measurement Science and Technology, vol. 23, no. 4, pp. 1-7, 2012.

[54] Y. Wang and H. Huang, "Optical fiber corrosion sensor based on laser light reflection," Smart Materials and Structures, vol. 20, no. 8, Article ID 085003, pp. 1-7, 2011.

[55] L. Rodriguez-Cobo, A. T. Marques, J. M. Lopez-Higuera, J. L. Santos, and O. Frazao, "New design for temperature-strain discrimination using fiber Bragg gratings embedded in laminated composites," Smart Materials and Structures, vol. 22, no. 10, pp. 1-10, 2013.

[56] S. Pirozzi, "Multi-point force sensor based on crossed optical fibers," Sensors and Actuators A: Physical, vol. 183, pp. 1-10, 2012.

[57] D. H. Kim, J. W. Park, H. K. Kang, C. S. Hong, and C. G. Kim, "Measuring dynamic strain of structures using a golddeposited extrinsic Fabry-Perot interferometer," Smart Materials and Structures, vol. 12, no. 1, pp. 1-5, 2003.

[58] G. Cumunel, S. Delepine-Lesoille, and P. Argoul, "Long-gage optical fiber extensometers for dynamic evaluation of structures," Sensors and Actuators, A: Physical, vol. 184, pp. 1-15, 2012.

[59] T. K. Gangopadhyay, M. Majumder, A. Kumar Chakraborty, A. Kumar Dikshit, and D. Kumar Bhattacharya, "Fibre Bragg grating strain sensor and study of its packaging material for use in critical analysis on steel structure," Sensors and Actuators A: Physical, vol. 150, no. 1, pp. 78-86, 2009.

[60] L. B. Yuan, Q. B. Li, Y. J. Liang, J. Yang, and Z. H. Liu, "Fiber optic 2-D sensor for measuring the strain inside the concrete 
specimen," Sensors and Actuators A: Physical, vol. 94, no. 1, pp. 25-31, 2001.

[61] H. Y. Liu, D. K. Liang, J. Zeng, J. Jin, J. Wu, and J. Geng, "Design of a long-period fiber grating sensor for reinforcing bar corrosion in concrete," Journal of Intelligent Material Systems and Structures, vol. 23, no. 1, pp. 45-51, 2012.

[62] S. Yashiro, T. Okabe, and N. Takeda, "Damage identification in a holed CFRP laminate using a chirped fiber Bragg grating sensor," Composites Science and Technology, vol. 67, no. 2, pp. 286-295, 2007.

[63] G. Zhou, L. M. Sim, and J. Loughlan, "Damage evaluation of smart composite beams using embedded extrinsic Fabry-Perot interferometric strain sensors: bending stiffness assessment," Smart Materials and Structures, vol. 13, no. 6, pp. 1291-1302, 2004.

[64] S. Triollet, L. Robert, E. Marin, and Y. Ouerdane, "Discriminated measures of strain and temperature in metallic specimen with embedded superimposed long and short fibre Bragg gratings," Measurement Science and Technology, vol. 22, no. 1, Article ID 015202, 2011.

[65] W. Hong, Z. S. Wu, C. Q. Yang, C. F. Wan, G. Wu, and Y. F. Zhang, "Condition assessment of reinforced concrete beams using dynamic data measured with distributed long-gage macro-strain sensors," Journal of Sound and Vibration, vol. 331, no. 12, pp. 2764-2782, 2012.

[66] S. Li and Z. Wu, "Development of distributed long-gage fiber optic sensing system for structural health monitoring," Structural Health Monitoring, vol. 6, no. 2, pp. 133-143, 2007.

[67] M. Quirion and G. Ballivy, "Concrete strain monitoring with Fabry-Perot fiber-optic sensor," Journal of Materials in Civil Engineering, vol. 12, no. 3, pp. 254-261, 2000.

[68] C. E. Davis, P. Norman, C. Ratcliffe, and R. Crane, "Broad area damage detection in composites using fibre Bragg grating arrays," Structural Health Monitoring, vol. 11, no. 6, pp. 724-732, 2012.

[69] S. Villalba and J. R. Casas, "Application of optical fiber distributed sensing to health monitoring of concrete structures," Mechanical Systems and Signal Processing, vol. 39, no. 1-2, pp. 441-451, 2013.

[70] B. Torres, I. Payá-Zaforteza Ignacio, P. A. Calderón, and J. M. Adam, "Analysis of the strain transfer in a new FBG sensor for structural health monitoring," Engineering Structures, vol. 33, no. 2, pp. 539-548, 2011.

[71] K. Schröder, W. Ecke, M. Kautz, S. Willett, M. Jenzer, and T. Bosselmann, "An approach to continuous on-site monitoring of contact forces in current collectors by a fiber optic sensing system," Optics and Lasers in Engineering, vol. 51, no. 2, pp. 172179, 2013.

[72] M. Kim, "A smart health monitoring system with application to welded structures using piezoceramic and fiber optic transducers," Journal of Intelligent Material Systems and Structures, vol. 17, no. 1, pp. 35-44, 2006.

[73] J. C. Xu, G. Pickrell, X. W. Wang, W. Peng, K. Cooper, and A. Wang, "A novel temperature-insensitive optical fiber pressure sensor for harsh environments," IEEE Photonics Technology Letters, vol. 17, no. 4, pp. 870-872, 2005.

[74] M. J. García, J. A. Ortega, J. A. Chávez, J. Salazar, and A. Turó, “A novel distributed fiber-optic strain sensor," IEEE Transactions on Instrumentation and Measurement, vol. 51, no. 4, pp. 685690, 2002.

[75] T. Liu, M. Wu, Y. Rao, D. A. Jackson, and G. F. Fernando, "A multiplexed optical fibre-based extrinsic Fabry-Perot sensor system for in-situ strain monitoring in composites," Smart Materials and Structures, vol. 7, no. 4, pp. 550-556, 1998.

[76] Y. J. Sun, B. Shi, S. E. Chen, H. H. Zhu, D. Zhang, and Y. Lu, "Feasibility study on corrosion monitoring of a concrete column with central rebar using BOTDR," Smart Structures and Systems, vol. 13, no. 1, pp. 41-53, 2014.

[77] C. Lan, Z. Zhou, and J. Ou, "Monitoring of structural prestress loss in RC beams by inner distributed Brillouin and fiber Bragg grating sensors on a single optical fiber," Structural Control and Health Monitoring, vol. 21, no. 3, pp. 317-330, 2014.

[78] Z. Zhou, J. P. He, G. D. Chen, and J. P. Ou, "A smart steel strand for the evaluation of prestress loss distribution in posttensioned concrete structures," Journal of Intelligent Material Systems and Structures, vol. 20, no. 16, pp. 1901-1912, 2009.

[79] J. R. Casas and P. J. S. Cruz, "Fiber optic sensors for bridge monitoring," Journal of Bridge Engineering, vol. 8, no. 6, pp. 362 373, 2003.

[80] E. Mehrani, A. Ayoub, and A. Ayoub, "Evaluation of fiber optic sensors for remote health monitoring of bridge structures," Materials and Structures, vol. 42, no. 2, pp. 183-199, 2009.

[81] B. Glisic and D. Inaudi, "Development of method for inservice crack detection based on distributed fiber optic sensors," Structural Health Monitoring, vol. 11, no. 2, pp. 161-171, 2012.

[82] I. Talebinejad, C. Fischer, and F. Ansari, "Serially multiplexed FBG accelerometer for structural health monitoring of bridges," Smart Structures and Systems, vol. 5, no. 4, pp. 345-355, 2009.

[83] R. C. Tennyson, A. A. Mufti, S. Rizkalla, G. Tadros, and B. Benmokrane, "Structural health monitoring of innovative bridges in Canada with fiber optic sensors," Smart Materials and Structures, vol. 10, no. 3, pp. 560-573, 2001.

[84] R. Brönnimann, P. M. Nellen, and U. Sennhauser, "Application and reliability of a fiber optical surveillance system for a stay cable bridge," Smart Materials and Structures, vol. 7, no. 2, pp. 229-236, 1998.

[85] C. Rodrigues, F. Cavadas, C. Félix, and J. Figueiras, "FBG based strain monitoring in the rehabilitation of a centenary metallic bridge," Engineering Structures, vol. 44, pp. 281-290, 2012.

[86] C. Barbosa, N. Costa, L. A. Ferreira et al., "Weldable fibre Bragg grating sensors for steel bridge monitoring," Measurement Science and Technology, vol. 19, no. 12, Article ID 125305, 2008.

[87] A. Kerrouche, W. J. O. Boyle, T. Sun, and K. T. V. Grattan, "Design and in-the-field performance evaluation of compact FBG sensor system for structural health monitoring applications," Sensors and Actuators, A: Physical, vol. 151, no. 2, pp. 107$112,2009$.

[88] G. Kister, R. A. Badcock, Y. M. Gebremichael et al., "Monitoring of an all-composite bridge using Bragg grating sensors," Construction and Building Materials, vol. 21, no. 7, pp. 1599-1604, 2007.

[89] G. Kister, D. Winter, R. A. Badcock et al., "Structural health monitoring of a composite bridge using Bragg grating sensors. Part 1: evaluation of adhesives and protection systems for the optical sensors," Engineering Structures, vol. 29, no. 3, pp. 440448, 2007.

[90] M. R. Mokhtar, K. Owens, J. Kwasny et al., "Fiber-optic strain sensor system with temperature compensation for arch bridge condition monitoring," IEEE Sensors Journal, vol. 12, no. 5, pp. 1470-1476, 2012.

[91] F. Surre, T. Sun, and K. T. Grattan, "Fiber optic strain monitoring for long-term evaluation of a concrete footbridge under extended test conditionss," IEEE Sensors Journal, vol. 13, no. 3, pp. 1036-1043, 2013. 
[92] T. H. T. Chan, L. Yu, H. Y. Tam et al., "Fiber Bragg grating sensors for structural health monitoring of Tsing Ma bridge: background and experimental observation," Engineering Structures, vol. 28, no. 5, pp. 648-659, 2006.

[93] M. Yau, T. Chan, D. Thambiratnam, and H. Tam, "Static vertical displacement measurement of bridges using fiber bragg grating (FBG) sensors," Advances in Structural Engineering, vol. 16, no. 1, pp. 165-176, 2013.

[94] X. Zhao, J. Lu, R. C. Han, X. L. Kong, Y. H. Wang, and L. Li, "Application of multiscale fiber optical sensing network based on brillouin and fiber bragg grating sensing techniques on concrete structures," International Journal of Distributed Sensor Networks, vol. 2012, Article ID 310797, 10 pages, 2012.

[95] W. Chung, S. Kim, N. Kim, and H. Lee, "Deflection estimation of a full scale prestressed concrete girder using long-gauge fiber optic sensors," Construction and Building Materials, vol. 22, no. 3, pp. 394-401, 2008.

[96] Y. B. Lin, C. L. Pan, Y. H. Kuo, K. C. Chang, and J. C. Chern, "Online monitoring of highway bridge construction using fiber Bragg grating sensors," Smart Materials and Structures, vol. 14, no. 5, pp. 1075-1082, 2005.

[97] C. Rodrigues, C. Félix, A. Lage, and J. Figueiras, "Development of a long-term monitoring system based on FBG sensors applied to concrete bridges," Engineering Structures, vol. 32, no. 8, pp. 1993-2002, 2010.

[98] G. Jiang, M. Dawood, K. Peters, and S. Rizkalla, "Global and local fiber optic sensors for health monitoring of civil engineering infrastructure retrofit with FRP materials," Structural Health Monitoring, vol. 9, no. 4, pp. 309-322, 2010.

[99] W. Zhang, J. Gao, B. Shi, H. Cui, and H. Zhu, "Health monitoring of rehabilitated concrete bridges using distributed optical fiber sensing," Computer-Aided Civil and Infrastructure Engineering, vol. 21, no. 6, pp. 411-424, 2006.

[100] B. J. A. Costa and J. A. Figueiras, "Fiber optic based monitoring system applied to a centenary metallic arch bridge: design and installation," Engineering Structures, vol. 44, pp. 271-280, 2012.

[101] J. P. He, Z. Zhou, and O. Jinping, "Optic fiber sensor-based smart bridge cable with functionality of self-sensing," Mechanical Systems and Signal Processing, vol. 35, no. 1-2, pp. 84-94, 2013.

[102] H. Li, J. Ou, and Z. Zhou, "Applications of optical fibre Bragg gratings sensing technology-based smart stay cables," Optics and Lasers in Engineering, vol. 47, no. 10, pp. 1077-1084, 2009.

[103] D. Li, Z. Zhou, and J. Ou, "Development and sensing properties study of FRP-FBG smart stay cable for bridge health monitoring applications," Measurement, vol. 44, no. 4, pp. 722-729, 2011.

[104] D. S. Li, Z. Zhou, and J. P. Ou, "Dynamic behavior monitoring and damage evaluation for arch bridge suspender using GFRP optical fiber Bragg grating sensors," Optics and Laser Technology, vol. 44, no. 4, pp. 1031-1038, 2012.

[105] Z. Zhou, M. H. Huang, L. Q. Huang, J. P. Ou, and G. D. Chen, "An optical fiber bragg grating sensing system for scour monitoring," Advances in Structural Engineering, vol. 14, no. 1, pp. 67-78, 2011.

[106] Y. Lin, J. Chen, K. Chang, J. Chern, and J. Lai, "Real-time monitoring of local scour by using fiber Bragg grating sensors," Smart Materials and Structures, vol. 14, no. 4, pp. 664-670, 2005.

[107] Y. B. Lin, J. S. Lai, K. C. Chang, and L. S. Li, "Flood scour monitoring system using fiber Bragg grating sensors," Smart Materials and Structures, vol. 15, no. 6, pp. 1950-1959, 2006.

[108] W. Xiong, C. S. Cai, and X. Kong, "Instrumentation design for bridge scour monitoring using fiber Bragg grating sensors," Applied Optics, vol. 51, no. 5, pp. 547-557, 2012.
[109] F. Bastianini, M. Corradi, A. Borri, and A. D. Tommaso, "Retrofit and monitoring of an historical building using "smart" CFRP with embedded fibre optic Brillouin sensors," Construction and Building Materials, vol. 19, no. 7, pp. 525-535, 2005.

[110] P. Antunes, R. Travanca, H. Rodrigues et al., "Dynamic structural health monitoring of slender structures using optical sensors," Sensors, vol. 12, no. 5, pp. 6629-6644, 2012.

[111] Y. Q. Ni, Y. Xia, W. Y. Liao, and J. M. Ko, “Technology innovation in developing the structural health monitoring system for Guangzhou New TV Tower," Structural Control and Health Monitoring, vol. 16, no. 1, pp. 73-98, 2009.

[112] D. S. Li, L. Ren, H. N. Li, and G. B. Song, "Structural health monitoring of a tall building during construction with fiber Bragg grating sensors," International Journal of Distributed Sensor Networks, vol. 2012, Article ID 272190, 10 pages, 2012.

[113] X. W. Ye, Y. Q. Ni, and J. H. Yin, "Safety monitoring of railway tunnel construction using FBG sensing technology," Advances in Structural Engineering, vol. 16, no. 8, pp. 1401-1409, 2013.

[114] N. Metje, D. N. Chapman, C. D. F. Rogers, P. Henderson, and M. Beth, "An optical fiber sensor system for remote displacement monitoring of structures-prototype tests in the laboratory," Structural Health Monitoring, vol. 7, no. 1, pp. 51-63, 2008.

[115] C. Li, Y. Zhao, H. Liu, Z. Wan, C. Zhang, and N. Rong, "Monitoring second lining of tunnel with mounted fiber Bragg grating strain sensors," Automation in Construction, vol. 17, no. 5, pp. 641-644, 2008.

[116] C. Li, Y. Zhao, H. Liu et al., "Strain and back cavity of tunnel engineering surveyed by FBG strain sensors and geological radar," Journal of Intelligent Material Systems and Structures, vol. 20, no. 18, pp. 2285-2289, 2009.

[117] B. Glisic and Y. Yao, "Fiber optic method for health assessment of pipelines subjected to earthquake-induced ground movement," Structural Health Monitoring, vol. 11, no. 6, pp. 696-711, 2012.

[118] C. Zhang, X. Bao, I. F. Ozkan et al., "Prediction of the pipe buckling by using broadening factor with distributed Brillouin fiber sensors," Optical Fiber Technology, vol. 14, no. 2, pp. 109113, 2008.

[119] L. Glavind, I. S. Olesen, B. F. Skipper, and M. Kristensen, "Fiber-optical grating sensors for wind turbine blades: a review," Optical Engineering, vol. 52, no. 3, Article ID 030901, pp. 1-9, 2013.

[120] T. J. Arsenault, A. Achuthan, P. Marzocca, C. Grappasonni, and G. Coppotelli, "Development of a FBG based distributed strain sensor system for wind turbine structural health monitoring," Smart Materials and Structures, vol. 22, no. 7, Article ID 075027, 2013.

[121] S. W. Kim, W. R. Kang, M. S. Jeong, I. Lee, and I. B. Kwon, "Deflection estimation of a wind turbine blade using FBG sensors embedded in the blade bonding line," Smart Materials and Structures, vol. 22, no. 12, pp. 1-11, 2013.

[122] J. Burgmeier, W. Schippers, N. Emde, P. Funken, and W. Schade, "Femtosecond laser-inscribed fiber Bragg gratings for strain monitoring in power cables of offshore wind turbines," Applied Optics, vol. 50, no. 13, pp. 1868-1872, 2011.

[123] H. J. Bang, H. I. Kim, and K. S. Lee, "Measurement of strain and bending deflection of a wind turbine tower using arrayed FBG sensors," International Journal of Precision Engineering and Manufacturing, vol. 13, no. 12, pp. 2121-2126, 2012.

[124] Y. Ge, K. S. Kuang, and S. T. Quek, "Development of a low-cost bi-axial intensity-based optical fibre accelerometer for wind 
turbine blades," Sensors and Actuators A: Physical, vol. 197, pp. 126-135, 2013.

[125] K. Schroeder, W. Ecke, J. Apitz, E. Lembke, and G. Lenschow, "A fibre Bragg grating sensor system monitors operational load in a wind turbine rotor blade," Measurement Science and Technology, vol. 17, no. 5, pp. 1167-1172, 2006.

[126] K. S. Choi, Y. H. Huh, I. B. Kwon, and D. J. Yoon, "A tip deflection calculation method for a wind turbine blade using temperature compensated FBG sensors," Smart Materials and Structures, vol. 21, no. 2, Article ID 025008, pp. 1-9, 2012.

[127] L. S. Yan, Z. T. Zhang, P. Wang et al., "Fiber sensors for strain measurements and axle counting in high-speed railway applications," IEEE Sensors Journal, vol. 11, no. 7, pp. 1587-1594, 2011.

[128] C. Wei, C. Lai, S. Liu et al., "A fiber Bragg grating sensor system for train axle counting," IEEE Sensors Journal, vol. 10, no. 12, pp. 1905-1912, 2010.

[129] C. Wei, Q. Xin, W. H. Chung, S. Liu, H. Tam, and S. L. Ho, "Realtime train wheel condition monitoring by fiber Bragg grating sensors," International Journal of Distributed Sensor Networks, vol. 2012, Article ID 409048, 7 pages, 2012.

[130] M. L. Filograno, P. C. Guillen, A. Rodriguez-Barrios et al., "Realtime monitoring of railway traffic using fiber Bragg grating sensors," IEEE Sensors Journal, vol. 12, no. 1, pp. 85-92, 2012.

[131] R. M. C. M. Pimentel, M. C. B. Barbosa, N. M. S. Costa et al., "Hybrid fiber-optic/electrical measurement system for characterization of railway traffic and its effects on a short span bridge," IEEE Sensors Journal, vol. 8, no. 7, pp. 1243-1249, 2008.

[132] A. Kerrouche, J. Leighton, W. J. O. Boyle et al., "Strain measurement on a rail bridge loaded to failure using a fiber Bragg grating-based distributed sensor system," IEEE Sensors Journal, vol. 8, no. 12, pp. 2059-2065, 2008.

[133] A. Kerrouche, W. J. O. Boyle, Y. M. Gebremichael et al., "Field tests of fibre Bragg grating sensors incorporated into CFRP for railway bridge strengthening condition monitoring," Sensors and Actuators A: Physical, vol. 148, no. 1, pp. 68-74, 2008.

[134] D. Kang and W. Chung, "Integrated monitoring scheme for a maglev guideway using multiplexed FBG sensor arrays," NDT and E International, vol. 42, no. 4, pp. 260-266, 2009.

[135] W. Chung and D. Kang, "Full-scale test of a concrete box girder using FBG sensing system," Engineering Structures, vol. 30, no. 3, pp. 643-652, 2008.

[136] H. J. Yoon, K. Y. Song, J. S. Kim, and D. S. Kim, "Longitudinal strain monitoring of rail using a distributed fiber sensor based on Brillouin optical correlation domain analysis," NDT and E International, vol. 44, no. 7, pp. 637-644, 2011.

[137] C. Wang, H. Tsai, C. Chen, and H. Wang, "Railway track performance monitoring and safety warning system," Journal of Performance of Constructed Facilities, vol. 25, no. 6, pp. 577-586, 2011.

[138] M. Bocciolone, G. Bucca, A. Collina, and L. Comolli, "Pantograph-catenary monitoring by means of fibre Bragg grating sensors: results from tests in an underground line," Mechanical Systems and Signal Processing, vol. 41, no. 1-2, pp. 226-238, 2013.

[139] P. Boffi, G. Cattaneo, L. Amoriello et al., "Optical fiber sensors to measure collector performance in the pantograph-catenary interaction," IEEE Sensors Journal, vol. 9, no. 6, pp. 635-640, 2009.

[140] H. Pei, J. Yin, H. Zhu, C. Hong, W. Jin, and D. Xu, "Monitoring of lateral displacements of a slope using a series of special fibre Bragg grating-based in-place inclinometers," Measurement Science and Technology, vol. 23, no. 2, Article ID 025007, 2012.

[141] H. Pei, J. Yin, and W. Jin, "Development of novel optical fiber sensors for measuring tilts and displacements of geotechnical structures," Measurement Science and Technology, vol. 24, no. 9, Article ID 095202, 2013.

[142] G. Kister, D. Winter, Y. M. Gebremichael et al., "Methodology and integrity monitoring of foundation concrete piles using Bragg grating optical fibre sensors," Engineering Structures, vol. 29, no. 9, pp. 2048-2055, 2007.

[143] Y. Lu, B. Shi, G. Q. Wei, S. E. Chen, and D. Zhang, "Application of a distributed optical fiber sensing technique in monitoring the stress of precast piles," Smart Materials and Structures, vol. 21, no. 11, Article ID 115011, 2012.

[144] Y. S. Kim, H. J. Sung, H. W. Kim, and J. M. Kim, "Monitoring of tension force and load transfer of ground anchor by using optical FBG sensors embedded tendon," Smart Structures and Systems, vol. 7, no. 4, pp. 303-317, 2011.

[145] T. F. H. Legge, P. L. Swart, G. van Zyl, and A. A. Chtcherbakov, "A fibre Bragg grating stress cell for geotechnical engineering applications," Measurement Science and Technology, vol. 17, no. 5, pp. 1173-1179, 2006. 

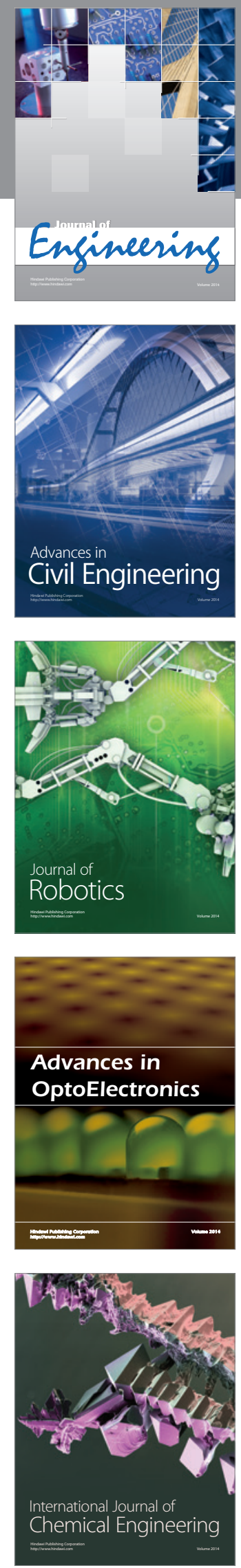

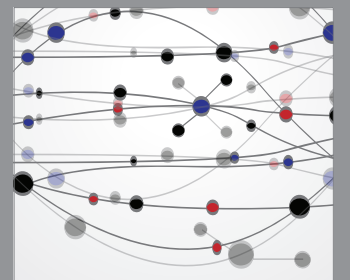

The Scientific World Journal
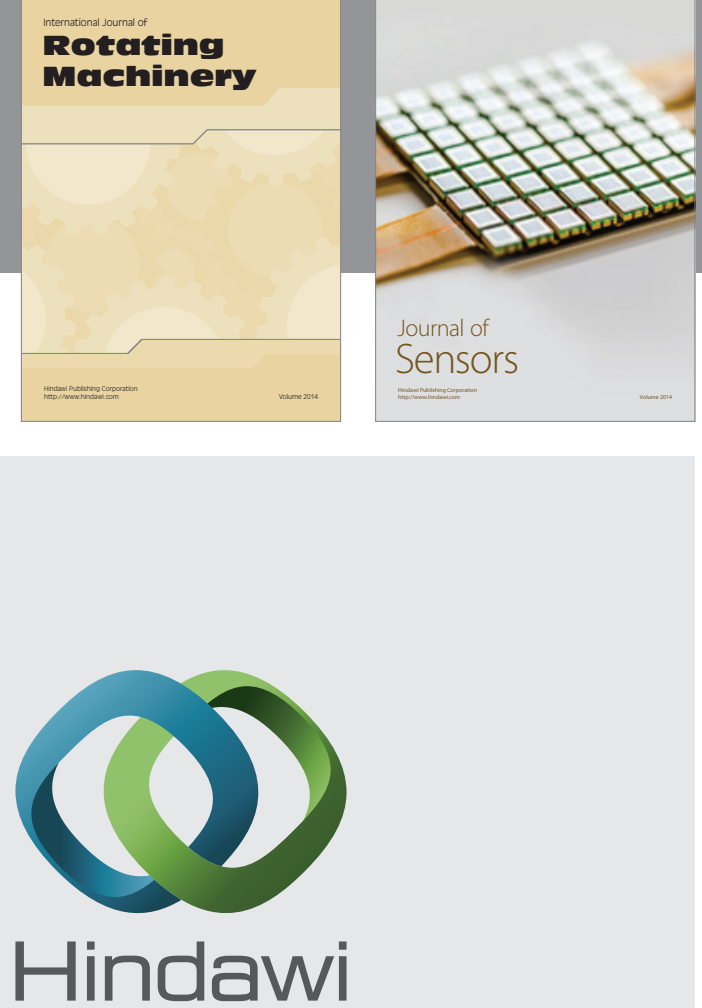

Submit your manuscripts at http://www.hindawi.com
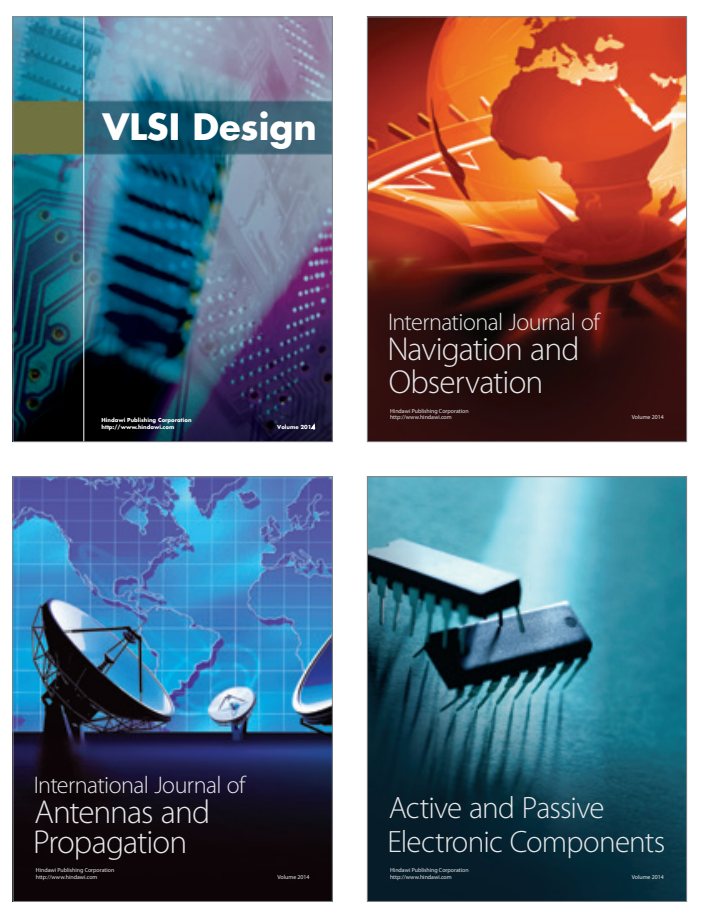
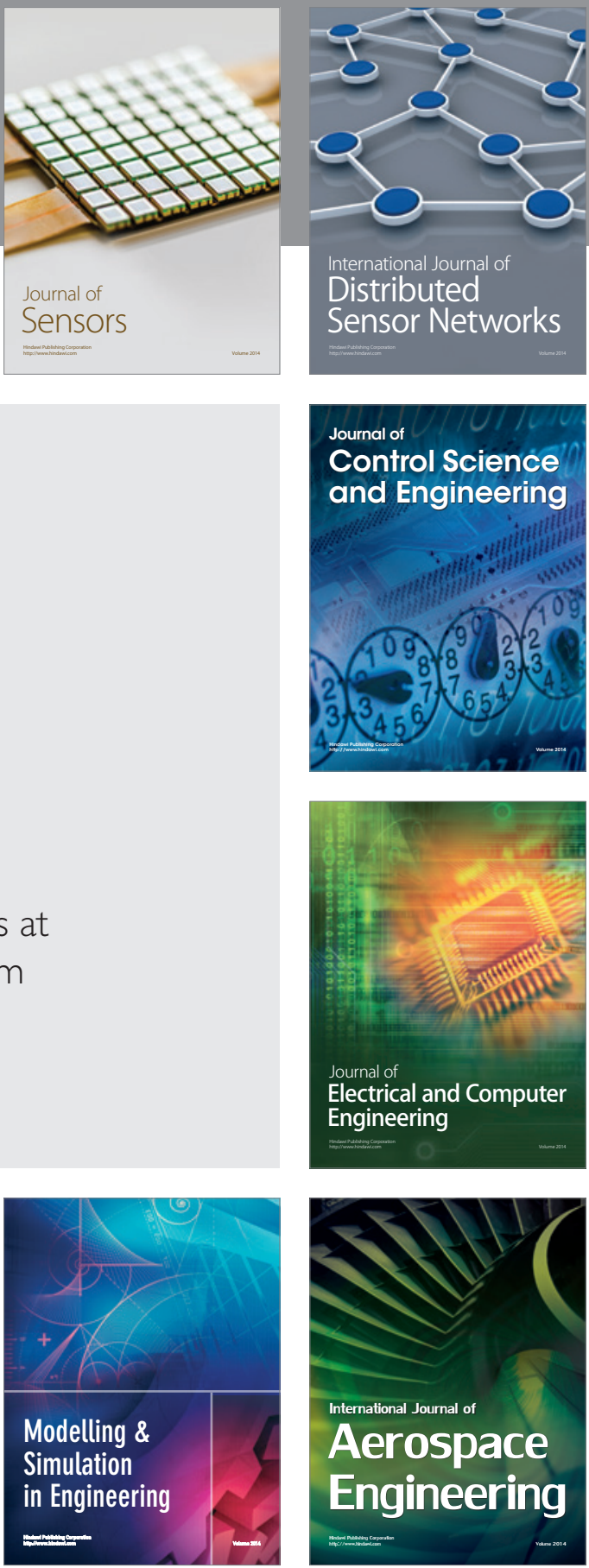

Journal of

Control Science

and Engineering
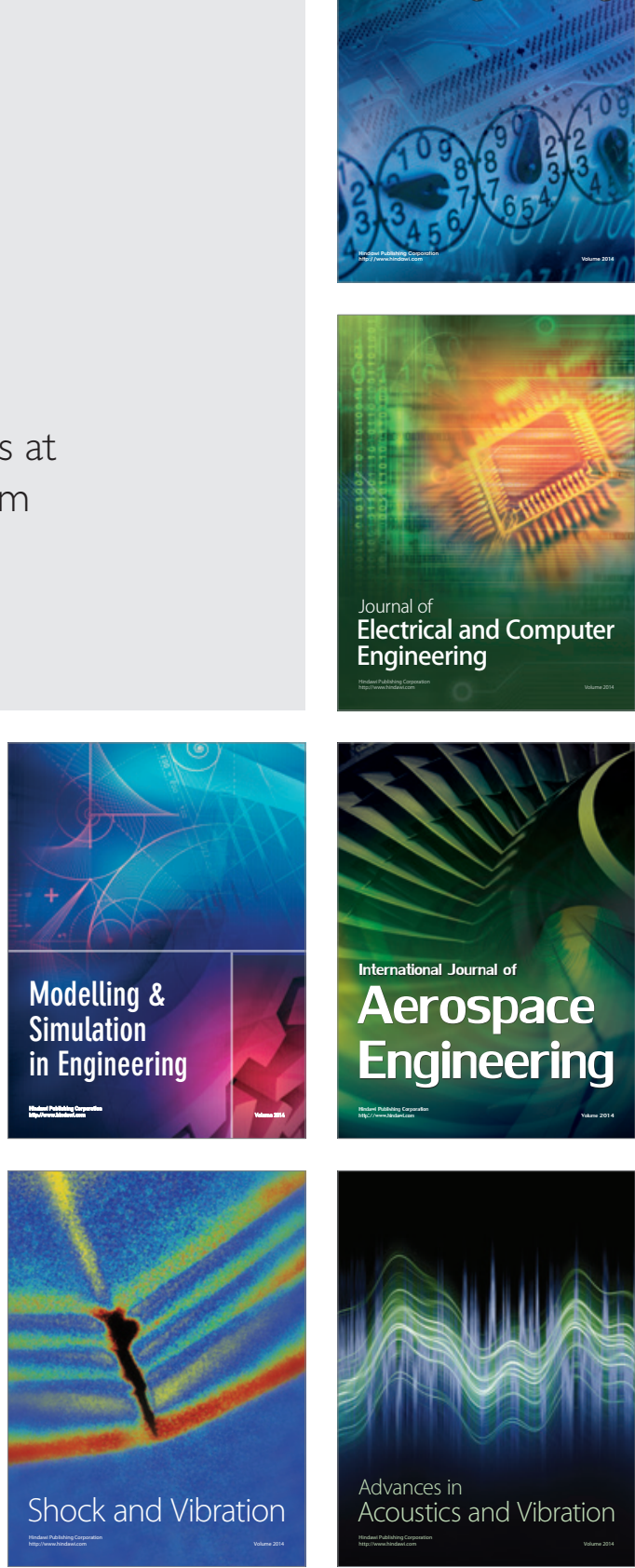